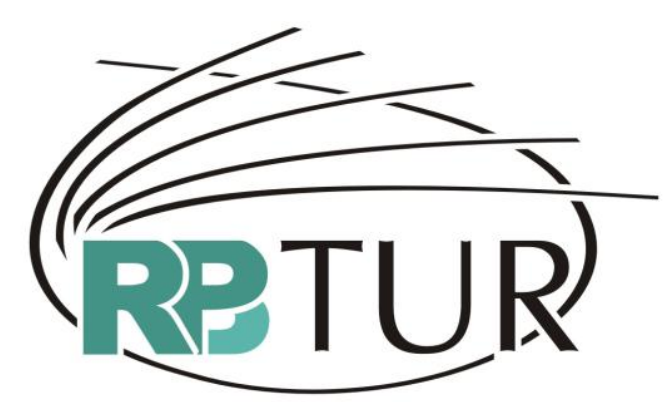

REVISTA BRASILEIRA DE PESQUISA EM TURISMO

\title{
RELATO - VIII SEMINÁRIO ANPTUR 2011 (BALNEÁRIO CAMBORIÚ,SC)
}

\author{
CONFERENCE REPORT - VIII SEMINÁRIO ANPTUR \\ (BALNEÁRIO CAMBORIÚ, SC, BRAZIL)
}

\section{RELATO - VIII SEMINÁRIO ANPTUR (BALNEÁRIO CAMBORIÚ, SC, BRASIL)}

\author{
Elizabeth Kyoko Wada ${ }^{1}$ \\ Susana de Araújo Gastal ${ }^{2}$
}

\section{Introdução}

O VIII Seminário ANPTUR 2011 foi realizado mediante promoção e organização conjunta entre a Associação Nacional de Pesquisa e PósGraduação, e a Pró-Reitoria de Pós-Graduação, Pesquisa, Extensão e Cultura da Universidade do Vale do Itajaí - UNIVALI. Reuniu um expressivo grupo de pesquisadores, estudiosos e profissionais que analisou e discutiu o tema

1 Doutorado em Ciências da Comunicação pela Universidade de São Paulo, Mestrado em Ciências da Comunicação pela Universidade de São Paulo, especialização em Administração Mercadológica pela EAESP/FGV, graduação em Turismo pelo Centro Universitário Ibero Americano Unibero e em Comunicação Social - Relações Públicas pela Universidade de São Paulo. É docente desde 1981; atualmente, dirige a Escola de Turismo e Hospitalidade, bem como a Pós-Graduação Stricto Sensu na Universidade Anhembi Morumbi. É diretora presidente da Associação Nacional de Pesquisa e Pós-Graduação em Turismo (ANPTUR) e presidente de MPI Brazil Chapter. Email: ekwada@anhembi.br

2 Possui graduação em Comunicação Social pela Pontifícia Universidade Católica do Rio Grande do Sul, mestrado em Artes Visuais pela Universidade Federal do Rio Grande do Sul e doutorado em Comunicação Social pela Pontifícia Universidade Católica do Rio Grande do Sul. Atualmente é Professora Doutora Adjunta 3, pesquisadora e orientadora do Mestrado em Turismo da Universidade de Caxias do Sul e Professora Adjunta do Curso de Turismo da Pontifícia Universidade Católica do RS. Ex-diretora científica da Associação Nacional de Pesquisa e PósGraduação em Turismo (ANPTUR). Email: sgastal@terra.com.br 
Turismo: Conhecimento,Tecnologias e Inovação. A programação envolveu uma série de atividades, iniciadas com o Encontro Binacional Brasil-Argentina, mesas redondas sobre o tema central do evento, sessões simultâneas dos grupos de trabalho, oficinas de estudo, encontro de editores e reunião de líderes de grupos de pesquisa.

O Turismo é uma área com íntima e forte consonância com os momentos que lhe são contemporâneos, pois o econômico, o social e o cultural influenciam diretamente nos estilos sociais de desfrute de tempo livre, lazer e viagens. Esta contingência exige igual sintonia da atividade acadêmica com a contemporaneidade, tanto na pesquisa como na docência. No cenário atual, significa considerar "o papel central da informação e do conhecimento no emergente padrão sócio-técnico-econômico; e a aceleração do processo de globalização e os impactos econômicos, políticos e sociais daí decorrentes" (LASTRES e ALBAGLI, 1999, p.7).

Nesse cenário de mudanças, torna-se necessário "desenvolver um quadro teórico-conceitual e uma base empírica que permitam lidar com a natureza ao mesmo tempo nova e complexa da presente fase" (LASTRES e ALBAGLI, 1999, p. 7). É nesse sentido, de busca de um quadro teórico-conceitual e de desenvolvimento de uma base em empírica que dê sustentação à pesquisa e ao ensino do Turismo dentro dos Programas de Pós-Graduação da área, que se organizou o VIII Seminário da Associação Nacional de Pesquisa e PósGraduação em Turismo - ANPTUR.

Os processos tecnológicos, na sua complexidade cada vez maior, influenciam a produção e alteram as formas tradicionais de difusão do conhecimento, assim como o seu conteúdo, uma vez que esses processos "estão impactando todo o universo social, e gerando novas dinâmicas aonde o conhecimento vai se tornando gradualmente central" (DOWBOR, 2001, p.4) e estratégico. A inovação aparece, nesses termos, como desafio a condicionar a organização social do conhecimento, no sentido de não se ater "apenas a fazer mais rápido e em maior escala os mesmos erros" (DOWBOR, 2001, p.2). 
Segundo o mesmo autor, o desafio contemporâneo é o de pensar e repensar o conhecimento em seu sentido mais amplo, nas suas implicações científicas, mas também econômicas e sociais. Ao contrário de outros momentos históricos, quando o conhecimento científico não teria estado no centro dos processos - e Dowbor cita Grécia e Roma clássicas, a antiga China e o antigo mundo islâmico -, atualmente o conhecimento estaria submetendo diretamente a sociedade, desencadeando processos e práticas, mas também reações. As novas práticas apóiam

[...] em novos saberes e competências, em novos aparatos e instrumentais tecnológicos, tanto como em novas formas de inovar e de organizar o processo produtivo, expressando-se assim uma nova economia ou um novo padrão técnico- econômico e ensejando também a necessidade de novas abordagens na própria teoria econômica e do valor. O desenvolvimento, a difusão e a convergência das tecnologias da informação e comunicação são vistos como centrais na conformação dessa nova dinâmica técnico-econômica (LASTRES e ALBAGLI, 1999, p. 8).

A tecnologia, associada ao código binário, encaminhou a era digital e a possibilidade de acumular informação de forma exponencial, o conhecimento deixando "de ser uma matéria para se tornar em 'fluído' de maleabilidade ilimitada" (DOWBOR, 2001, p.5). Esse conhecimento fluído imiscui-se por toda sociedade, colocando como desafio imediato organizar o armazenamento e a recuperação de dados, utilizando-se para tal de suportes cada vez mais sofisticados, variados em tamanho, perfis, funções e competências, associados a softwares para criar pontes entre usuários, entre usuário e máquina, entre máquina e outras máquinas, entre programas e informações, a partir de bancos de dados. Consequência, a educação se vê abalada nas suas formas, conteúdos e funções tradicionais, antes restritas a transmissão de conhecimentos. Uma alteração que é, na sua magnitude, uma mudança cultural.

Para as instituições acadêmicas, o primeiro grande desafio frente ao conhecimento fluído, é mexer com um campo científico antes "muito claro e determinado" (AUDY E MOROSINI, 2007, p.506), levando inclusive a que os 
autores prefiram a expressão educação pós-secundária à educação superior, por melhorar caracterizar "as mudanças de concepção e operacionalização" (AUDY E MOROSINI, 2007, p.506) do sistema do terceiro grau e de seus desdobramentos nas pós-graduações. Tal cenário levou a que a área da Administração tomasse a dianteira na teorização sobre a questão ou questões do processo, tratado como gestão do conhecimento, no qual o conceito inovação se colocaria com destaque.

Coloca-se no desdobramento o desafio de passar das ações inovadoras isoladas, para uma cultura de inovação na qual "o docente deve atuar como catalisador de um continuum de mudanças, trocas e renovações que caracterizam a sociedade do conhecimento em que vivemos" (AUDY e MOROSINI, 2007, p.507)

A continuidade exige dos pesquisadores disciplina para criar, ferramentas que apóiem os processos de criação, análise e fluxo de idéias, sustentabilidade no sentido de respeitar prazos, orçamentos e qualidade, participação em programas de aprimoramento e na construção de redes, considerando seus nós (indivíduos e grupos de indivíduos) e laços, viabilizando a relação entre os nós para ativar os fluxos de informação.

As redes, segundo Audy e Morosini (2007), devem reforçar a identidade dos pesquisadores, dando-Ihes suporte emocional, legitimidade pública e acesso a recursos. Ainda em termos de pesquisa, torna-se fundamental o estímulo à internacionalização das parcerias interinstitucionais, assim como o estabelecimento de centros de excelência ou de pesquisa, locais, com um enfoque internacional. Na linha da inovação, é necessário que o sistema estabelecido leve ao reconhecimento de trabalhos realizados, via divulgação de resultados de pesquisa. Por fim, a mobilidade acadêmica deve significar, também, recepção a pesquisador estrangeiro. Das pesquisas se exige uma visão sempre maior do universo social e natural, resultado de um trabalho em equipe e em redes.

O objetivo principal foi o de reunir a comunidade científica da área para análise e discussão das questões relacionadas ao Turismo: conhecimento, 
tecnologias e inovação, buscando que o aprofundamento, o crescimento e a consolidação acadêmica do campo do Turismo, Hospitalidade, Lazer e áreas afins, seja contemporâneo ao tempo social e acadêmico em que se insere em termos teóricos, metodológicos e éticos. Registre-se que essa inquietação nasceu na lista de discussão mantida pela ANPTUR, portanto, do consenso entre os seus membros.

\section{Seminário da ANPTUR}

O seminário nacional da ANPTUR, a cada ano, testemunha e registra o crescimento e maturidade do campo do Turismo no Brasil. Em 2011, em sua oitava edição, recebeu 303 trabalhos, vindos de todos os pontos do Brasil e de países como o Chile, um sinal que nossa produção teórica cresceu e se diversificou em termos geográficos, mas também na diversidade e aprofundamento dos temas propostos. Nesse ano, contou com a ativa participação da Comissão Científica formada no VII ANPTUR, em 2010, composta pelos Profs. Drs. Susana Gastal, Mirian Rejowski, Francisco dos Anjos e Roberto Bartholo.

Os 147 trabalhos (48,5\% do total de trabalhos avaliados), que compuseram os grupos de trabalho do VIII ANPTUR, abrangeram as preocupações dos pesquisadores brasileiros em Turismo, com ênfase em áreas como planejamento, políticas públicas e gestão. Houve, também, uma presença importante de abordagens sobre acessibilidade, sustentabilidade e utilização de tecnologia. Destacam-se, ainda, os trabalhos reunidos nos grupo que discutem diferentes facetas do ensino do Turismo.

O número total de inscritos no VII Seminário ANPTUR foi de 198 participantes, sendo a maioria $(71,7 \%)$ de autores de trabalhos, portanto pesquisadores, mestres, doutores, docentes e/ou discentes de programas de pós-graduação stricto sensu. Todos os coordenadores dos programas filiados à ANPTUR estavam presentes ou se fizeram representar; destacaram-se os pesquisadores vinculados aos programas filiados à ANPTUR, em especial da 
ISSN: $1982-6125$

Universidade Anhembi Morumbi e da Universidade do Vale do Itajaí. Estiveram representadas 94 Instituições e Entidades, de 21 Estados Brasileiros, além do Distrito Federal. Na edição de 2011, o Seminário ANPTUR contou com a participação de 8 instituições estrangeiras, de três países - Portugal, Argentina e Chile.

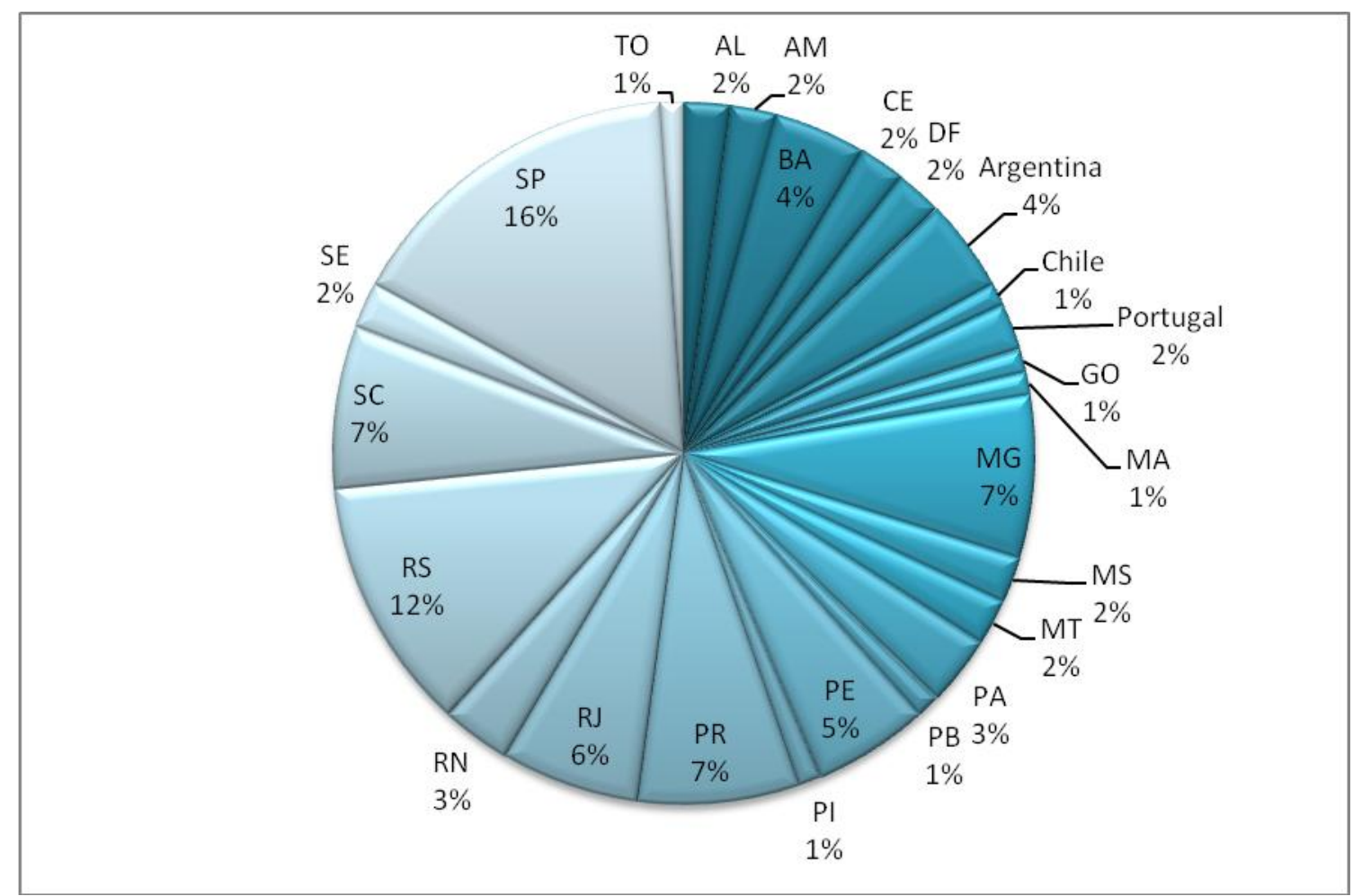

Figura 1 - Distribuição Geográfica dos Inscritos

Fonte: Inscrições VIII Seminário ANPTUR (2011)

O VIII ANPTUR não se restringiu aos grupos de trabalhos. Sob a temática central estruturaram-se as conferências e as oficinas.

O tema central foi abordado em mesa redonda com representante da Capes e da ANPTUR, a qual norteou as atividades subsequentes, em especial as reuniões dos Grupos de Trabalho (GTs), coordenadas por doutores da área.

Além das sessões dos GTs, ocorreram duas reuniões de grupos de afinidades - a V Reunião de Pesquisadores Líderes e o V Encontro de Editores Científicos -, e quatro oficinas de estudo com doutores da área, definidas mediante demandas dos membros ANPTUR enviadas à Diretoria Científica. Na 
sessão de premiação, houve a outorga de Prêmio Tese Destaque ANPTUR 2010

- Categoria Dissertação, às melhores dissertações defendidas em 2010:

Quadro 1 - Resultados do Prêmio TESE DESTAQUE Anptur concedido em 2011

\begin{tabular}{|c|c|c|c|c|}
\hline & Nome & Título da Dissertação & IES & Orientador \\
\hline $1^{\circ}$ lugar & Daniela Santos & $\begin{array}{l}\text { Acessibilidade para pedestres } \\
\text { com deficiência em espaços } \\
\text { turísticos urbanos: a situação } \\
\text { da área central de Balneário } \\
\text { Camboriú) }\end{array}$ & UNIVALI & $\begin{array}{l}\text { Profa. Dra. Josildete } \\
\text { Pereira de Oliveira }\end{array}$ \\
\hline 20 lugar & Alessandra Carvalho & $\begin{array}{l}\text { Envelhecimento, turismo e } \\
\text { lazer: expectativa de } \\
\text { sociabilidade }\end{array}$ & UAM & $\begin{array}{l}\text { Profa. Dra. Maria do } \\
\text { Rosário R. Salles }\end{array}$ \\
\hline $3^{\circ}$ lugar & Guilherme Bridi & $\begin{array}{lcc}\text { Formação e } & \text { atuação do } \\
\text { turismólogo no cenário das } \\
\text { agencias } & \text { de turismo: } \\
\text { contrapondo competências }\end{array}$ & UCS & $\begin{array}{l}\text { Profa. Dra. Marcia } \\
\text { Maria Cappellano } \\
\text { dos Santos }\end{array}$ \\
\hline
\end{tabular}

Houve a homenagem a Pesquisador Turístico Destaque, com prêmio concedido ao Prof. Dr. Eduardo Abdo Yázigi que o recebeu das mãos do Prof. Dr. Mário Carlos Beni. Na sequência, ocorreu a Sessão de Encerramento, com uma mesa redonda com as Profas. Dras. Laurentina Vareiro - Instituto Politécnico do Cávado e do Aveiro - Portugal; Doris V. de Meene Ruschmann, da UNIVALI e Susana de Araújo Gastal, da UCS. Realizou-se, também, a posse da Diretoria eleita em assembléia realizada em 3 de outubro de 2011. A chapa eleita para o período 2011/2013 é composta por: Elizabeth Kyoko Wada, Diretora Presidente; Márcia Maria Capellano dos Santos, Diretora VicePresidente; Francisco dos Anjos, Diretor Científico; Cléria Botelho Costa, Diretora Acadêmica; Rosana Mara Mazaro, Diretora de Relações Institucionais Nacionais e Internacionais; Ricardo de Gil Torres, Diretor AdministrativoFinanceiro. Também foram empossados os membros do Conselho Fiscal: Susana de Araújo Gastal, Afonso Getúlio Zucarato e Fábio Perdigão Vasconcelos, bem como os suplentes Mirian Rejowski, Doris Van de Meene Ruschmann e Roberto dos Santos Bartholo Junior.

A diretora presidente da ANPTUR, Elizabeth Wada, agradeceu os diretores e conselheiros da gestão 2009/2011, a UNIVALI e as agências de fomento, os participantes, a equipe organizadora e a equipe de apoio do Seminário, 
ressaltando resultados parciais dos dois dias do evento. Comunicou e convidou a todos para o IX Seminário da ANPTUR, a ser realizado em 2012, em São Paulo, com o apoio do Mestrado em Hospitalidade da Universidade Anhembi Morumbi.

\section{Considerações Finais}

O VIII Seminário da ANPTUR 2011 contou com 198 inscritos, ou seja, 20\% abaixo do número de 2010 (245 inscritos), redução facilmente compreendida pela alteração do critério de valorização para participação em eventos científicos estabelecido pela CAPES. Os participantes se mostraram ativos e entusiasmados no decorrer de todo o evento: nas oficinas, nas sessões de abertura, de premiação e encerramento, nas reuniões e encontros paralelos e, principalmente, nas sessões dos grupos de trabalho das quatro divisões científicas.

O número total de trabalhos aprovados (147 de 303 submetidos - 48,5\% de aprovação) foi inferior a 2010 (175), a 2009 (198), a 2008 (201) e a 2007 (172), e segundo os coordenadores de GTs e os próprios participantes, houve melhora significativa na qualidade dos mesmos. Apesar da consolidação do evento em seu caráter estritamente científico e da própria comunidade científica dos campos do Turismo e da Hospitalidade, percebe-se o impacto das resoluções sobre a eliminação de anais como publicação válida para pontuação nos programas stricto sensu. Há necessidade de se rever a estrutura do evento, a fim de garantir o alto nível das discussões e a riqueza das reflexões em grupo, desassociando tais características da mecânica estritamente relacionada à apresentação de trabalhos e a publicação de anais.

Dentre as recomendações que haviam sido sugeridas em 2010, foram atendidas as seguintes:

- Criação de uma Comissão Científica, liderada pela Diretoria Científica, a fim de dinamizar as questões referentes a conteúdo, avaliação e publicação. 
- Oferta de quatro oficinas de estudo, conforme demandas da comunidade científica da área.

- Avaliação das temáticas dos Grupos de Trabalho, consolidando os que apresentaram consistência e aglutinando em grupos os que ainda são emergentes, reduzindo assim o número de GTs e de Divisão Científica.

- Incluir um formulário para o Relatório dos GTs, com um campo para a indicação dos melhores trabalhos a serem publicados na RBTUR - Revista Brasileira de Pesquisa em Turismo, editada pela ANPTUR.

As sugestões e/ou recomendações para o próximo Seminário da ANPTUR a ser realizado em 2012 foram as seguintes:

- Continuidade da dinâmica adotada na Reunião de Pesquisadores Líderes e no Encontro de Editores, com a volta de expositores sobre temas atuais e vivências profissionais relevantes de interesse dos participantes desses dois grupos de afinidades.

- Oferta de três oficinas de estudo, conforme demandas da comunidade científica da área.

- Elaborar uma ficha eletrônica de avaliação do Evento a ser enviada a todos os participantes e a tabulação respectiva dos dados para aprimoramento do evento.

- Promover, ao final do Evento, uma reunião de avaliação com os coordenadores de GTs e representantes das Oficinas e do Encontro/Reunião, redigindo um documento final a ser disponibilizado a todos os participantes e autoridades da área, onde constem os principais resultados, as tendências teórico-metodológicas e as possíveis aplicações das pesquisas apresentadas.

\section{Referências}

AUDY, J.L.N. e MOROSINI, M.C. Inovação e interdisciplinaridade na universidade. Porto Alegre: Edipucrs, 2007 
WADA, Elizabeth Kyoko; GASTAL, Susana de Araújo. Relato - VIII Seminário ANPTUR 2011 Balneário Camboriú/SC). Revista Brasileira de Pesquisa em Turismo. v.5, n.3, p.438-447, dez.2011.

ISSN: $1982-6125$

DOWBOR, L. Tecnologias do conhecimento: os desafios da educação. In. http://dowbor.org/tecnconhec.asp, 2001.

LASTRES, H. e ALBAGLI, S. Informação e globalização na era do conhecimento. Rio de Janeiro: Campus, 1999, p.7.

Texto recebido em novembro de 2011.

Aprovado para publicação em dezembro de 2011. 